\title{
HOW SORGHUM CROSSES ARE MADE
}

\author{
T. E. NAFziger
}

$\mathrm{T}$ HE sorghum heads which are not to be used for crossing, should either be bagged, or should be entirely removed from the stalks before their anthers open. This prevents pollen from these heads from falling upon the flowers of the experimental plants before the emasculation [removal of stamens] of their flowers or while the process of emasculation is taking place.

A branch or "ray" is selected from a panicle [flower cluster] of a plant of a pure strain, which has none of the anthers or stigmas exposed. The blossoms must be emasculated before the anthers emerge. Care must be taken however, not to open the blossoms while in their earlly stages of formation, as injury may result to the interior, causing the pistils and the glumes [corresponding to petals in ordinary flowers] to dry up.

\section{A BLUNT NEEDLE MAKES A GOOD .TOOL}

In emasculating the blossoms, an instrument should be used that is not so sharp as to puncture the anthers, and yet not so blunt as to mutilate the interior of the flower. A steel dissecting needle with the point slightly blunted, can be employed with a fair degree of success in removing the stamens. A common pin could be used, were it not for the slight possible chance of injury to the flower due to the material used in the construction of the pin.

All of the flowers on the branch chosen, except ten or a dozen, are then carefully removed from the branch. These remaining flowers are emasculated by prying the glumes apart very carefully with the dissecting needle. Placing the needle under the three stamens, they are removed one by one from the interior of the flower. If an anther

has been punctured during the process of removal, or if the hands have been in contact with punctured anthers, the hands and the needle should be washed in alcohol, and allowed to dry thoroughly before proceeding with the work.

The branch is bagged, after the flowers are emasculated, with a small paraffined paper bag, to prevent pollen from reaching the stigmas of the emasculated flowers. The panicle which has the attached branch, is also bagged (preferably with a waxed bag) to save the pollen for the reciprocal cross. The panicle is then tagged with a label showing the number of the strain, the number of the plant, the number of the reciprocal, and the date when emasculation was done. A representative tag is reproduced in the figure below.

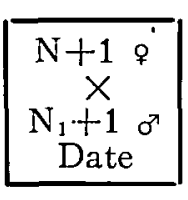

The same procedure as outlined above, is followed in emasculating the flowers of the strain upon which the reciprocal cross is to be made. The tag on the panicle of the reciprocal would show the following.

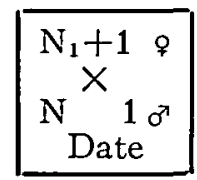

The first line in the notation on the tag indicates that the tagged plant is the female $N_{1}$ and that $N$ is the male plant. 
The time elapsing between emasculation and pollination depends upon weather conditions. Ordinarily, the time is about seventy-two hours. The pollen is transferred to the stigmas with a small brush, directly from the bag in which it has collected. The pollinated ray, and the panicle are again properly bagged. In forty-eight hours the bag may be removed from the former.

The milos [a type of sorghum] have proven to be the most difficult to cross, the flowers appearing to dry up, shortly after emasculation takes place. When an anther is punctured during the process of emasculation, the affected flower should be removed from the ray. Too much pollen should not be placed upon the stigmas.

If all the panicles are bagged, thus preventing the pollen from blowing about, the bags may be removed from the rays after each day's work of pollination is completed. The stamens do not emerge during the heat of the day, but emerge freely during the night.

The work herein described was carried on by the writer on the plant breeding plots of the Department of Botany and Plant Breeding, of the Kansas State Agricultural College, during the summer of 1916, under the direction of Professor H. F. Roberts.

\section{Training Little Children for the New Liee}

Congress has recently recognized the educational needs of little children by making an appropriation to the United States Bureau of Education, to enable it to promote kindergarten education in the several states and territories.

This act is timely, for our people are being rudely awakened to the need of better training for citizenship than our boys and girls are now receiving. They realize the urgent necessity of properly equipping our children for the tremendous tasks they will be called upon to perform after the war is ended.

The Council for National Defense states that there are nearly $4,000,000$ children in the United States who can not receive the benefits of kindergarten training either because there are no kindergartens at all or not enough.

Training for citizenship cannot be- gin too early according to the United States Commissioner of Education, who for months has been issuing, in cooperation with the National Kindergarten Association the series of articles which this paper is printing, to provide better training for little ones in the home.

A drive is now on to have more kindergartens opened throughout the country and parents are circulating petitions to present to their boards of education. The General Federation of Women's Clubs, the National Congress of Mothers and Parent Teacher Associations, Suffrage and labor organizations are all deeply interested in this subject and great hopes are entertained that the drive will receive the hearty cooperation of local school authorities thoroughout the country. 